\title{
Hypofractionated radiotherapy for localized prostate cancer
}

\author{
Stefan Höcht ${ }^{1} \cdot$ Daniel M. Aebersold ${ }^{2}$. Clemens Albrecht ${ }^{3} \cdot$ Dirk Böhmer $^{4} \cdot$ Michael Flentje $^{5}$ Ute Ganswindt $^{6}$ \\ Tobias Hölscher $^{7}$ Thomas Martin ${ }^{8}$ Felix Sedlmayer ${ }^{*}$ Frederik Wenz $^{10} \cdot$ Daniel Zips $^{11} \cdot$ Thomas Wiegel $^{12}$
}

Received: 19 June 2016 / Accepted: 30 July 2016 / Published online: 14 September 2016

(C) The Author(s) 2016. This article is available at SpringerLink with Open Access.

\begin{abstract}
Aim This article gives an overview on the current status of hypofractionated radiotherapy in the treatment of prostate cancer with a special focus on the applicability in routine use.

Methods Based on a recently published systematic review the German Society of Radiation Oncology (DEGRO) expert panel added additional information that has become available since then and assessed the validity of the information on outcome parameters especially with respect to long-term toxicity and long-term disease control.

Results Several large-scale trials on moderate hypofractionation with single doses from 2.4-3.4 Gy have recently finished recruiting or have published first results suggestive of equivalent outcomes although there might be a trend for increased short-term and possibly even long-term tox-
\end{abstract}

S. Höcht, D.M. Aebersold, C. Albrecht, D. Böhmer, M. Flentje, U. Ganswindt, T. Hölscher, T. Martin, F. Sedlmayer, F. Wenz,

D. Zips and T. Wiegel for the Prostate Cancer Expert Panel of the German Society of Radiation Oncology (DEGRO) and the Working Party Radiation Oncology of the German Cancer Society (DKG-ARO)

Stefan Höcht

stefan.hoecht@googlemail.com

1 Radiologie, Nuklearmedizin und Strahlentherapie, Xcare Gruppe, Saarlouis, Germany

2 Universitätsklinik für Radio-Onkologie, Inselspital, University of Bern, Bern, Switzerland

3 Klinik für Radioonkologie und Gemeinschaftspraxis für Strahlentherapie, Klinikum Nürnberg Nord, Universitätsklinikum der Paracelsus Medizinischen Privatuniversität, Nuremberg, Germany

4 Klinik für Radioonkologie und Strahlentherapie, Charité Universitätsmedizin, Berlin, Germany icity. Large phase 3 trials on extreme hypofractionation with single doses above 4.0 Gy are lacking and only very few prospective trials have follow-up periods covering more than just 2-3 years.

Conclusion Until the results on long-term follow-up of several well-designed phase 3 trials become available, moderate hypofractionation should not be used in routine practice without special precautions and without adherence to the highest quality standards and evidence-based dose fractionation regimens. Extreme hypofractionation should be restricted to prospective clinical trials.

Keywords Hypofractionation · Prostate cancer · Radiotherapy

5 Klinik und Poliklinik für Strahlentherapie, Universitätsklinikum Würzburg, Würzburg, Germany

6 Klinik und Poliklinik für Strahlentherapie und Radioonkologie, Ludwig-Maximilians-Universität München, Munich, Germany

$7 \quad$ Klinik und Poliklinik für Strahlentherapie und Radioonkologie, Universitätsklinikum Carl Gustav Carus, Technische Universität Dresden, Dresden, Germany

8 Klinik für Strahlentherapie und Radioonkologie, Klinikum Bremen-Mitte, Bremen, Germany

9 Universitätsklinik für Radiotherapie und Radio-Onkologie, Landeskrankenhaus, Universitätsklinikum der Paracelsus Medizinischen Privatuniversität, Salzburg, Austria

10 Klinik für Strahlentherapie und Radioonkologie, Universitätsmedizin Mannheim, Universität Heidelberg, Mannheim, Germany

11 Universitätsklinik für Radioonkologie, Universitätsklinikum Tübingen, Tübingen, Germany

12 Abteilung Strahlentherapie, Universitätsklinikum Ulm, Ulm, Germany 


\section{Hypofraktionierte Radiotherapie des lokalisierten Prostatakarzinoms}

\section{Zusammenfassung}

Ziel Diese Übersichtsarbeit soll den aktuellen Status der hypofraktionierten Radiotherapie des Prostatakarzinoms mit dem Fokus auf die Anwendung in der Routinetherapie darstellen.

Methoden Basierend auf einem kürzlich erschienen systematischen Review zur Hypofraktionierung sind durch das DEGRO Expertengremium zusätzliche, in der Zwischenzeit verfügbar gewordene Informationen mit berücksichtigt worden. Die Validität der Aussagen zu Ergebnissen wurde speziell im Hinblick auf die Langzeittoxizität und -erkrankungskontrolle bewertet.

Ergebnisse Mehrere große Phase-3-Studien zur moderaten Hypofraktionierung mit Dosen von 2,4-3,4 Gy pro Fraktion haben die Rekrutierung beendet oder bereits erste Resultate berichtet, die auf eine Äquivalenz hindeuten, wenngleich es einen Trend zu vermehrter akuter und möglicherweise auch später Toxizität gibt. Große Phase-3-Studien zur extremen Hypofraktionierung mit Einzeldosen von über 4,0 Gy gibt es bisher nicht, und nur sehr wenige prospektive Studien haben ein Follow-up von mehr als 2 bis 3 Jahren.

Schlussfolgerung Vor Veröffentlichung der Langzeitdaten der existierenden, gut geplanten und durchgeführten prospektiv-randomisierten Studien sollte eine moderate Hypofraktionierung in der Routine nicht ohne besondere Vorsicht und unter Einhaltung höchster Qualitätsstandards und Verwendung evidenzbasierter Schemata für Dosis und Fraktionierung angewendet werden. Eine extreme Hypofraktionierung sollte prospektiven klinischen Studien vorbehalten bleiben.

Schlüsselwörter Hypofraktionierung - Prostatakarzinom · Strahlentherapie

\section{Introduction}

Prostate cancer is one of the predominant malignancies in men throughout the western world. Radiotherapy and prostatectomy are the main interventions applied in patients with a life expectancy long enough to justify possible treatment-related side effects and long-term sequelae. Generally, there is a broad consensus that both modalities offer a similar chance of a cure but due to the different profiles of side effects and impact on functional domains, they have their specific pros and cons; therefore, counselling of patients is much more time-consuming compared to other malignant diseases, where the superiority of a respective treatment option is unquestioned. One of the major drawbacks of external beam radiotherapy is the long time span needed to deliver a complete course of radiotherapy, usually amounting up to 2 months.

Mainly driven by a shortage of treatment facilities and/or long travelling distances in countries with healthcare systems providing fewer but larger therapeutic units, hypofractionation, i. e. shortening of overall treatment time by delivering larger doses per fraction up to a lower total dose, has attracted growing interest. In treating women with breast cancer, moderate hypofractionation (i. e. daily doses of approximately $2.7 \mathrm{~Gy}$ ) is nowadays broadly accepted as an alternative to standard fractionation [1-3]. Prostate cancer as a relatively slowly growing malignancy shows a better prognosis than many other tumors, necessitating very long follow-up times to evaluate the safety profile of therapeutic modifications in terms of disease control as well as side effects; therefore, any adoption of new treatment concepts has to be scrutinized to a high degree. Especially in the last few years, a rapid increase in reports on hypofractionated radiotherapy for prostate cancer has been noted, which prompted the present overview, supplementing a recently published systematic review [4] and including guidance for daily practice.

\section{Biology}

Traditionally, external beam irradiation regimens have been developed over several decades and the mode of application, i. e. doses per fraction of 1.8-2.0 Gy given 5 times per week up to total doses exceeding 70 Gy have been shown to be safe, with severe side effects being very rare events. Most cancers and normal tissues behave differently when exposed to radiation. The linear-quadratic equation serves as a biomathematical model commonly applied to describe fractionation sensitivity of tissues and to calculate isoeffective doses for different doses per fraction. Tissue-specific $\alpha / \beta$ values derived from this model can be estimated from clinical and preclinical data. As almost every human organ is composed of different tissue types, the $\alpha / \beta$ values may be different for distinct endpoints evaluated within the same organ, emphasizing the need for cautious interpretation when testing new fractionation schemes.

Retrospective data derived from different modes of radiotherapy application and fractionation initially suggested very low $\alpha / \beta$ values for prostate cancer in the range of $1.5 \mathrm{~Gy}$, i. e. lower than the $\alpha / \beta$ values of the surrounding dose-limiting normal tissues. These data led to the hypothesis that hypofractionation improves the therapeutic ratio for radiotherapy of prostate cancer. Based on this hypothesis randomized trials were initiated. The controversial discussion on fractionation sensitivity of prostate cancer is further complicated by the existence of a time factor [5]. Prostate cancer is often a slowly growing tumor which may predict 
a low $\alpha / \beta$ value (and hence a high fractionation sensitivity) and a negligible time factor (loss of effect by increase in overall treatment time); however, a large retrospective analysis on external beam radiotherapy for prostate cancer comprising 4839 patients demonstrated a significant and clinically relevant time factor of $0.24 \mathrm{~Gy} /$ day with a $95 \%$ confidence interval of $0.03-0.44$ Gy/day [6]. Of note, the effect of androgen deprivation on the time factor is unknown. Although the time factor for prostate cancer is not as pronounced as in other tumor types, it has important implications not only for trial design but also for clinical practice. As often with hypofractionation, the overall treatment time is shorter than for conventional fractionation, thus the suspected superiority of hypofractionation might not only be explained by fractionation sensitivity or in other words the $\alpha / \beta$ value for prostate cancer might be higher than initially suspected [7]. This is of high relevance for the design of biologically driven fractionation schedules. The lack of superiority of hypofractionation observed in the Fox Chase trial $[8,18]$ does not support the assumption of a very low $\alpha / \beta$ value for prostate cancer but suggests that the fractionation sensitivities of prostate cancer and the dose-limiting surrounding normal tissues overlap.

Given the contradictory and lacking evidence the German Society of Radiation Oncology (DEGRO) expert panel drew the following conclusions:

- The assumption of an $\alpha / \beta$ value for prostate cancer of as low as $1.5 \mathrm{~Gy}$ might lead to an overestimation of the effects of hypofractionation.

- Fractionation sensitivity of prostate cancer and surrounding tissues does not decisively differ; therefore, hypofractionated and accelerated study designs with a reduced total dose seem promising and may be possible without any deterioration of the therapeutic ratio.

- The time factor may contribute in part to the efficacy of hypofractionation.

- Due to the described uncertainties in assuming fractionation sensitivities and the steep dose-response effects for tumor control and for normal tissue toxicity, fractionation concepts have to be tested in well-designed randomized trials, such as the CHHiP, HYPRO and the RTOG 0415 studies and should not be mathematically derived.

- Only evidence-based fractionation schedules should be used outside of clinical trials.

- Treatment interruptions leading to prolonged overall treatment times can have negative consequences and have to be adequately compensated.

\section{Technology}

The technological basis for external beam radiotherapy has continuously developed over the last 2 decades and a modern standard is now broadly available. A highly conformal radiotherapy, e. g. intensity modulated radiotherapy (IMRT), with daily verification of the prostate position by image-guided radiation therapy (IGRT) is the prerequisite for all hypofractionation concepts. The target volume concept in radiation therapy of prostate cancer forms the basis for understanding the reduction in normal tissue complication probability (NTCP) by IGRT. Due to histological multifocality of prostate cancer, the target of radiotherapy is the entire prostate gland and also a subclinical infiltration zone around the prostate needs to be considered carefully to improve the probability of tumor control [9].

As radiation therapy is fractionated in clinical practice, i. e. applied in small daily doses over several weeks a further safety margin, the planning target volume (PTV) needs to be defined around the clinical target volume (CTV). The PTV includes possible positioning errors of the CTV by potential inaccuracies in the daily set up, organ movement from day to day (interfractional organ movement) and during beam application (intrafractional organ movement). By definition, this safety margin within the PTV around the CTV contains only normal tissue. Another mandatory factor for hypofractionated radiotherapy of prostate cancer is a daily verification of target volumes immediately before irradiation. By visualizing the localization of the prostate, the positioning error and the interfractional organ movement can be widely corrected, thus reducing the PTV in the ideal case without intra-fractional movement to the CTV. Intrafractional movement can be minimized by fast beam application, e.g. rotational IMRT and/or using high dose rate flattening filter free (FFF) beam delivery. Institutional IGRT protocols may specifically account for intrafractional corrections [10]. As a result of these technical developments, the volume of normal tissue receiving high doses and thus the NTCP might be reduced. In the clinical routine, several IGRT methods have been established. Especially in the case of prostate cancer, IGRT procedures should allow 3-dimensional imaging with soft tissue contrast or fiducialbased techniques (intraprostatic markers) should be applied.

\section{Moderate hypofractionation}

Defining standard fractionation with single doses of 1.8-2.0 Gy is easier than defining the dose commonly regarded as hypofractionation. For purposes of this review, the arbitrary definition of moderate hypofractionation with doses per fraction in the range of 2.2 up to $4.0 \mathrm{~Gy}$ and extreme hypofractionation with a single dose beyond $4.0 \mathrm{~Gy}$ has been chosen.

Data from eight randomized trials on moderate hypofractionation with appropriate sample size are available (table 1; [8, 11-25]). Single doses ranging from 2.4 Gy to 3.4 Gy 
Table 1 Prospective randomized studies on moderate hypofractionated external beam radiotherapy for prostate cancer

\begin{tabular}{|c|c|c|c|c|c|c|c|}
\hline Study & $n$ & $\begin{array}{l}\text { Median } \\
\text { FU } \\
\text { (months) }\end{array}$ & $\begin{array}{l}\text { Risk groups/ } \\
\text { Gleason } \\
\text { scores }\end{array}$ & Techniques & Regimen $(\mathrm{TD} / \mathrm{f} \mathrm{x} / S D)$ & Outcome & $\begin{array}{l}\text { Toxicity e = early, } \\
\text { otherwise: late tox }\end{array}$ \\
\hline $\begin{array}{l}\text { RTOG } 0415 \\
\text { Lee et al. [11] }\end{array}$ & $\begin{array}{l}542 \\
550\end{array}$ & 70 & Low risk & $\begin{array}{l}\text { 3D-CRT/ } \\
\text { IMRT } \\
\text { daily IGRT }\end{array}$ & $\begin{array}{l}73.8 \mathrm{~Gy} / 41 \mathrm{fx} / 1.8 \mathrm{~Gy} \\
70 \mathrm{~Gy} / 28 \mathrm{fx} / \\
2.5 \mathrm{~Gy} \\
\text { no ADT }\end{array}$ & $\begin{array}{l}5 \text { years DFS } \\
85.3 \%(\mathrm{NS}) \\
5 \text { years DFS } \\
86.3 \%\end{array}$ & $\begin{array}{l}\text { G } 2 \text { GI } 11.4 \%(p= \\
0.05) \\
\text { G } 2 \text { GU } 20.5 \%(p= \\
0.09) \\
\text { G } 2 \text { GI } 18.3 \% \\
\text { G } 2 \text { GU } 26.2 \%\end{array}$ \\
\hline Lukka et al. [12] & $\begin{array}{l}466 \\
470\end{array}$ & 68 & $\begin{array}{l}60 \% \text { GS } \leq 6 \\
31 \% \text { GS } 7 \\
9 \% \text { GS } 8-10\end{array}$ & $\begin{array}{l}\text { 3DCRT } \\
\text { No IGRT }\end{array}$ & $\begin{array}{l}52.5 \mathrm{~Gy} / 20 \mathrm{fx} / 2.63 G y \\
66 \mathrm{~Gy} / 33 \mathrm{fx} / \\
2.0 \mathrm{~Gy} \\
\text { no ADT }\end{array}$ & $\begin{array}{l}5 \text { years } \\
\text { FFBF } 47 \% \\
\text { (NS) } \\
5 \text { years } \\
\text { FFBF } 42 \%\end{array}$ & $\begin{array}{l}\text { G } 3-4 \text { GU + GI } \\
3.2 \% \\
\text { (NS) } \\
\text { G 3-4 GU + GI } \\
3.2 \%\end{array}$ \\
\hline $\begin{array}{l}\text { HYPRO } \\
\text { Aluwini et al. } \\
{[13,14]} \\
\text { Incrocci et al. } \\
{[15]}\end{array}$ & $\begin{array}{l}397 \\
407\end{array}$ & 60 & $\begin{array}{l}27 \% \text { interme- } \\
\text { diate } \\
73 \% \text { high }\end{array}$ & $\begin{array}{l}95 \% \\
\text { IMRT/ } \\
\text { IGRT }\end{array}$ & $\begin{array}{l}78 \mathrm{~Gy} / 39 \mathrm{fx} / \\
2.0 \mathrm{~Gy} \\
64.6 \mathrm{~Gy} / 19 \mathrm{fx} / 3.4 G y \\
66 \% \text { ADT }\end{array}$ & $\begin{array}{l}5 \text { years RFS } \\
77.1 \%(\mathrm{NS}) \\
5 \text { years RFS } \\
80.5 \%\end{array}$ & $\begin{array}{l}3 \text { years } \mathrm{G} 2+\mathrm{GU} \\
39 \% \\
3 \text { years } \mathrm{G} 3+ \\
\text { GU12.9\% } \\
3 \text { years G2+ GI } \\
17.7 \% \\
(3 \text { years G3+ GU } p= \\
0.02) \\
3 \text { years G2+ GU } \\
41.3 \% \\
3 \text { years G3+ GU } \\
19.0 \% \\
3 \text { years G2+ GI } \\
21.9 \%\end{array}$ \\
\hline $\begin{array}{l}\text { CHHiP } \\
\text { Dearnaley et al. } \\
{[16,17]}\end{array}$ & \multicolumn{2}{|c|}{$\begin{array}{l}1065 / 37 \mathrm{f} 62 \\
1074 / 20 \mathrm{fx} \\
1077 / 19 \mathrm{fx}\end{array}$} & $\begin{array}{l}15 \% \text { low } \\
73 \% \text { interme- } \\
\text { diate } \\
12 \% \text { high }\end{array}$ & $\begin{array}{l}\text { IMRT } \\
\text { IGRT not } \\
\text { mandatory }\end{array}$ & $\begin{array}{l}74 \mathrm{~Gy} / 37 \mathrm{fx} / \\
2.0 \mathrm{~Gy} \\
60 \mathrm{~Gy} / 20 \mathrm{fx} / \\
3.0 \mathrm{~Gy} \\
57 \mathrm{~Gy} / 19 \mathrm{fx} / \\
3.0 \mathrm{~Gy} \\
97 \% \mathrm{ADT}\end{array}$ & $\begin{array}{l}5 \text { years PFS } \\
\text { (NS) } \\
88.3 \% \\
(37 \mathrm{fx}) \\
\text { vs. } \\
90.6 \% \\
(20 \mathrm{fx}) \\
\text { vs. } \\
85.9 \% \\
(19 \mathrm{fx})\end{array}$ & $\begin{array}{l}\text { Acute } G 2+G I(p< \\
0.0001) \\
25 \%(37 \mathrm{fx}) \\
38 \%(20 \mathrm{fx}) \\
38 \%(19 \mathrm{fx}) \\
5 \text { years } G 2+G I \\
(\text { RTOG, NS) } \\
13.7 \%(37 \mathrm{fx}) \\
11.9 \%(20 \mathrm{fx}) \\
11.3 \%(19 \mathrm{fx}) \\
5 \text { years } G 2+G U \\
(\text { RTOG, NS) } \\
9.1 \%(37 \mathrm{fx}) \\
11.7 \%(20 \mathrm{fx}) \\
6.6 \%(19 \mathrm{fx})\end{array}$ \\
\hline $\begin{array}{l}\text { Fox Chase } \\
\text { Pollack et al. [8, } \\
\text { 18] } \\
\text { Shaikh et al. } \\
\text { [19]abs }\end{array}$ & $\begin{array}{l}151 \\
152\end{array}$ & 68 & $\begin{array}{l}34 \% \text { GS } \leq 6 \\
47 \% \text { GS } 7 \\
19 \% \text { GS } 8-10\end{array}$ & $\begin{array}{l}\text { IMRT } \\
\text { daily } \\
\text { IGRT }\end{array}$ & $\begin{array}{l}70.2 \mathrm{~Gy} / 26 \mathrm{fx} / \\
2.7 \mathrm{~Gy} \\
76 \mathrm{~Gy} / 38 \mathrm{fx} / \\
2.0 \mathrm{~Gy} \\
46 \% \mathrm{ADT}\end{array}$ & $\begin{array}{l}5 \text { years } \\
\text { BCDF } 23 \% \\
(\mathrm{NS}) \\
5 \text { years } \\
\text { BCDF } 21 \%\end{array}$ & $\begin{array}{l}5 \text { years G 2+ GU } \\
13 \%(\mathrm{NS}) \\
5 \text { years G2+ GI } 9 \% \\
(\mathrm{NS}) \\
5 \text { years G2+ GU } \\
22 \% \\
5 \text { years G2+ GI } 9 \% \\
\text { incontinence worse at } \\
3 \text { years }(p=0.03) \text { but } \\
\text { not at } 5 \mathrm{y}\end{array}$ \\
\hline
\end{tabular}


Table 1 Prospective randomized studies on moderate hypofractionated external beam radiotherapy for prostate cancer (Continued)

\begin{tabular}{|c|c|c|c|c|c|c|c|}
\hline Study & $n$ & $\begin{array}{l}\text { Median } \\
\text { FU } \\
\text { (months) }\end{array}$ & $\begin{array}{l}\text { Risk groups/ } \\
\text { Gleason } \\
\text { scores }\end{array}$ & Techniques & Regimen (TD/fx/SD) & Outcome & $\begin{array}{l}\text { Toxicity e = early, } \\
\text { otherwise: late tox }\end{array}$ \\
\hline Yeoh et al. [20] & $\begin{array}{l}108 \\
109\end{array}$ & 90 & n.s. & $\begin{array}{l}\text { 2D/3DCRT } \\
\text { No IGRT }\end{array}$ & $\begin{array}{l}55 \mathrm{~Gy} / 20 \mathrm{fx} / \\
2.75 G y \\
64 \mathrm{~Gy} / 32 \mathrm{fx} / \\
2.0 G y \\
\text { no ADT }\end{array}$ & $\begin{array}{l}7.5 \text { years } \\
\text { FFBF } 53 \% \\
(p<0.05) \\
7.5 \text { years } \\
\text { FFBF } 34 \%\end{array}$ & $\begin{array}{l}4 \text { years GU; HR: } 1.58 \\
(95 \% \mathrm{CI}, 1.01-2.47 \text { ) } \\
\text { favoring hypofrac- } \\
\text { tionation, but no } \\
\text { difference GI + GU } \\
\text { at } 5 \text { years FU }\end{array}$ \\
\hline $\begin{array}{l}\text { Kuban et al. } \\
\text { [21]abs/Hoffman } \\
\text { et al. [22] }\end{array}$ & $\begin{array}{l}102 \\
101\end{array}$ & 60 & $\begin{array}{l}28 \% \text { low } \\
71 \% \\
\text { intermediate } \\
1 \% \text { high }\end{array}$ & $\begin{array}{l}\text { IMRT } \\
\text { IGRT }\end{array}$ & $\begin{array}{l}72 \mathrm{~Gy} / 30 \mathrm{fx} / \\
2.4 \mathrm{~Gy} \\
75.6 \mathrm{~Gy} / 42 \mathrm{fx} / \\
1.8 \mathrm{~Gy} \\
21 \% \mathrm{ADT}\end{array}$ & $\begin{array}{l}5 \text { years } \\
\text { FFBF } 96 \% \\
\text { (NS) } \\
5 \text { years } \\
\text { FFBF } 92 \%\end{array}$ & $\begin{array}{l}5 \text { years G2+ GU } \\
16 \%(\mathrm{NS}) \\
5 \text { years G2+ GI } 10 \% \\
\text { (NS) } \\
5 \text { years G2+ GU } \\
17 \% \\
5 \text { years G2+ GI } 5 \%\end{array}$ \\
\hline $\begin{array}{l}\text { Arcangeli et al. } \\
{[23-25]}\end{array}$ & $\begin{array}{l}83 \\
85\end{array}$ & 70 & $\begin{array}{l}26 \% \text { GS }<7 \\
74 \% \text { GS }>7\end{array}$ & $\begin{array}{l}\text { 3DCRT } \\
\text { No IGRT }\end{array}$ & $\begin{array}{l}62 \mathrm{~Gy} / 20 \mathrm{fx} / \\
3.1 \mathrm{~Gy} \\
80 \mathrm{~Gy} / 40 \mathrm{fx} / \\
2.0 \mathrm{~Gy} \\
100 \% \mathrm{ADT}\end{array}$ & $\begin{array}{l}5 \text { years } \\
\text { FFBF } 85 \% \\
(p=0.065) \\
5 \text { years } \\
\text { FFBF } 74 \%\end{array}$ & $\begin{array}{l}3 \text { years G 2+ GU } \\
16 \%(\mathrm{NS}) \\
3 \text { years G } 2+\text { GI } 17 \% \\
\text { (NS) } \\
3 \text { years G 2+ GU } \\
11 \% \\
3 \text { years G 2+ GI 14\% }\end{array}$ \\
\hline
\end{tabular}

$3 D C R T$ three-dimensional conformal radiotherapy, $a b s$ data derived from abstract, $A D T$ androgen deprivation therapy, $B C D F$ biochemical or clinical disease failure, $C I$ confidence interval, $D F S$ disease free survival, $F F B F$ freedom from biochemical failure, $F U$ follow-up, $f x$ fractions, $G I$ gastrointestinal, $G$ grade, $G S$ Gleason score, $G U$ genitourinary, $H R$ hazard ratio, IGRT image-guided radiation therapy, $I M R T$ intensity-modulated radiation therapy, $N S$ not significant, $n$. $s$. not stated, $R F S$ relapse-free survival, $s s$ statistically significant, $S D$ single dose, $T D$ total dose

and total doses from 52.5 Gy to 72.0 Gy were applied in the experimental arms. The largest study by far, the CHHiP trial with more than 3200 patients included was first partially published as a subset of 457 patients [17] and just recently 5-year follow-up data became available [16]. Two other large studies, the RTOG 0415 and the HYPRO trial have also just been published in detail $[11,15]$. The studies from Yeoh et al. [20, 26] and Lukka et al. [12] are of limited interest, as total doses applied in each of the study arms nowadays would be regarded as far below established standards of care. This is true for the techniques used in these studies as well. Some of these studies did use or at least permit hypofractionation in conjunction with simultaneous integrated boost techniques (e. g. CHHIP and HYPRO) and only very rarely examined the treatment of the pelvic lymph nodes with hypofractionated external beam radiotherapy $[8$, $18]$.

\section{Toxicity}

Whereas the median follow-up might already be sufficient to estimate outcome in terms of side effects, this is not true for the primary endpoint of disease control where longer follow-up is needed. Some caveats exist. In the HYPRO study, cumulative acute gastrointestinal (GI) toxicity grade 2 and worse was significantly increased $(42 \%$ vs. $31.2 \%, p=0.0015)$ in the hypofractionated arm, leading to the statement that hypofractionated radiotherapy was not non-inferior in terms of acute side effects [14]. In the gastrointestinal subitems evaluated, there was a marked difference with respect to increased stool frequency $\geq 6$ times a day $(15 \%$ vs. $8 \%, p=0.0035)$ and in pain needing drugs (9\%vs. $5 \%, p=0.021)$. In genitourinary (GU) toxicity there was no difference in general but in the subitem increased frequency at night more than 7 times (grade 3) there again was a significant increase in the hypofractionation group ( $12 \%$ vs. $7 \%, p=0.019)$. Late toxicity of the HYPRO study has been recently reported [13]. Grade 2 or worse GU toxicity at 3 years was increased (hazard ratio HR 1.16) from $39.0 \%$ to $41.3 \%$ and grade 2 or worse gastrointestinal toxicity at 3 years increased from $17.7 \%$ to $21.9 \%$ (HR 1.19). Especially cumulative grade 3 or worse late GU toxicity was significantly higher with an increase from $12.9 \%$ to $19.0 \%(p=0.021)$. The subitems that were of special concern were nycturia $\geq 6$ ( $1 \%$ vs. $6 \%, p=0.0005$ ), incontinence ( $14 \%$ vs. $20 \%, p=0.04)$ and stool frequency $\geq 6$ ( $3 \%$ vs. $7 \%, p=0.034$ ). Thus, the authors again had to state that with respect to late toxicity non-inferiority could not be shown. As there was no significant difference, neither in 5-year relapse-free survival nor in treatment failure, the authors concluded that their hypofractionated radiother- 
apy regimen could not be regarded as the new standard of care [15].

With regard to acute side effects the results of the CHHiP trial pointed in the same direction as there was a statistically significant increase in acute grade 2 or more GI toxicity in the two hypofractionated arms of the trial $(25 \%$ vs. $38 \% p<0.0001)$ [16]. The 5 -year biochemical or clinical failure-free survival rates were in a relatively narrow range from $85.9 \%$ for the $57 \mathrm{~Gy}$ in 19 fractions regimen up to $90.6 \%$ for $60 \mathrm{~Gy}$ in 20 fractions and the conventionally fractionated radiotherapy regimen lying just in between with $88.3 \%$. Due to the predefined hazard ratios (HR) for the 57 Gy regimen, non-inferiority in comparison to standard fractionation could not be claimed, whereas for the 60 Gy regimen non-inferiority was documented. At 5 years there were no significant differences in grade 1, grade 2, grade 3 or worse bowel, bladder or sexual symptoms.

The Fox Chase and the HYPRO studies noted an increased risk for late GU toxicity in patients with impaired urinary function prior to the commencement of radiotherapy $[15,18,27]$. For other outcome domains of interest, such as sexual functioning and well-being $[28,29]$ there are not enough data available yet.

a

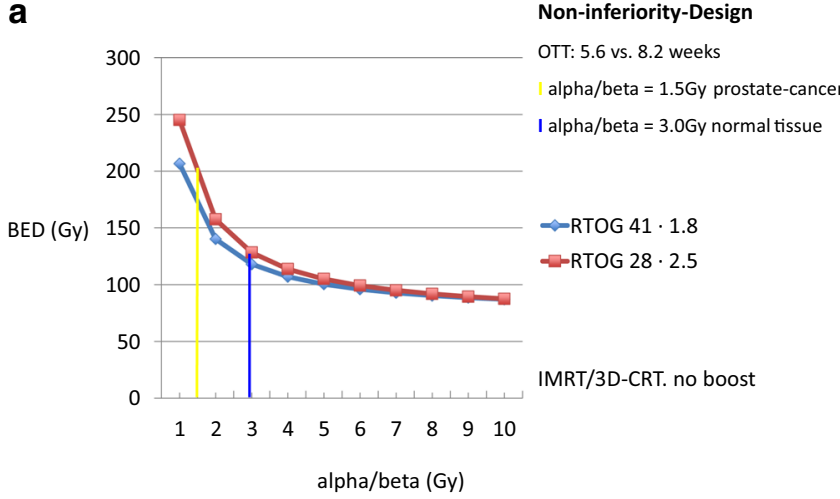

C

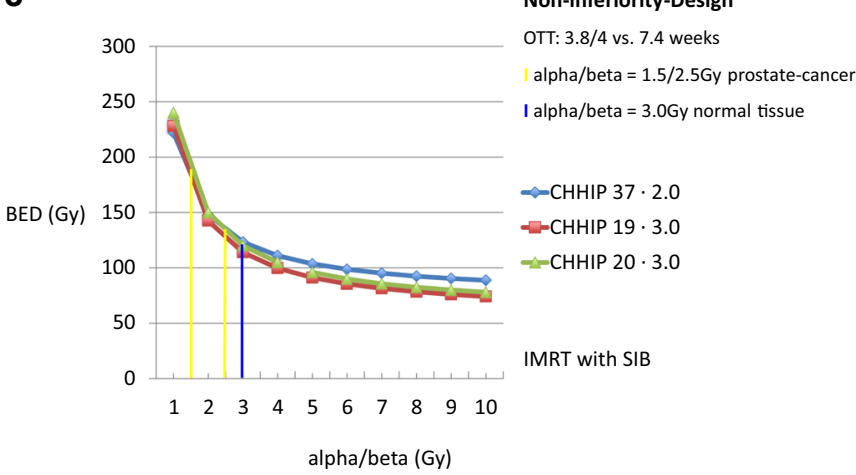

In the RTOG 0415 study, no differences in early GI or GU adverse events were observed. Late grade 2 and 3 GI adverse events were approximately $60 \%$ more likely in men who were assigned to treatment with hypofractionated RT (HR, 1.55-1.59). Similarly, late grade 2 and 3 GU adverse events were more likely in men treated with hypofractionated radiotherapy (HR, 1.31 to 1.56). No differences in more severe events were observed [11].

Of note, both the HYPRO and RTOG studies might have used higher biologically effective doses in their experimental (hypofractionated) arms than in the control cohorts. Both the HYPRO and the RTOG trial were based on the assumption of $\alpha / \beta$ values of $1.5 \mathrm{~Gy}$ for prostate cancer. In the RTOG trial, even if assuming an $\alpha / \beta$ of 2 Gy for prostate cancer, the experimental arm resulted in an EQD2 (equivalent dose for a 2 Gy fraction) of 79 Gy vs. 70 Gy for the standard treatment. Likewise, in the HYPRO study, the respective groups were treated with an EQD2 of 87 Gy vs. $78 \mathrm{~Gy}$ to the prostate. Assuming an $\alpha / \beta$ value of $3.0 \mathrm{~Gy}$ for late rectal reactions, the EQD2 values would have been $6 \mathrm{~Gy}$ higher in the experimental arms of both trials and the observed differences in toxicity rates may be also attributable to biologically effective higher doses in the HF arms (see Fig. 1a-d), where the different fractionation schemes of the

b

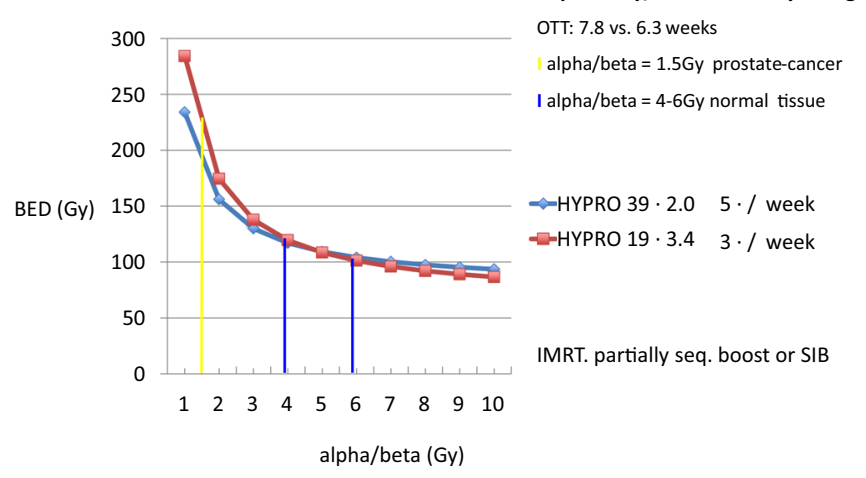

d

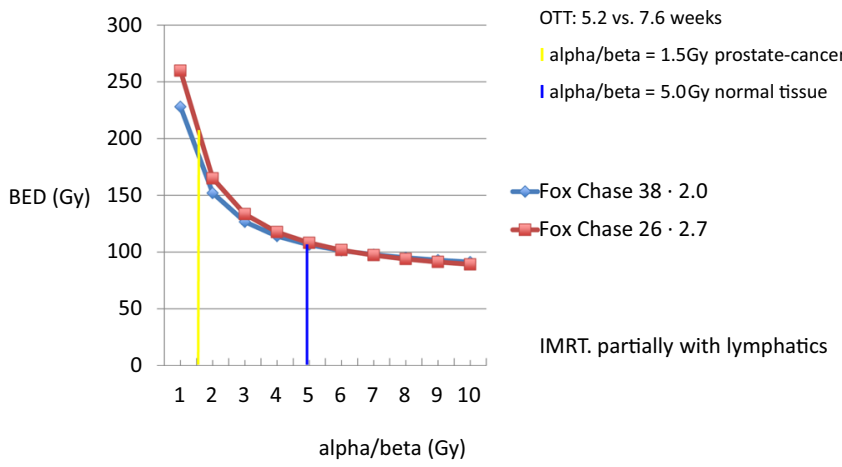

Fig. 1 Major randomized trials on moderate hypofractionation in prostate cancer. Biologically effective doses (BED) are depicted and compared for different alpha/beta values. The assumptions made in the study protocols on alpha/beta values for prostate cancer and organs at risk are shown in vertical lines. OTT overall treatment time, IMRT intensity modulated radiotherapy, SIB simultaneous integrated boost, 3D-CRT 3-dimensional conformal radiotherapy 
most relevant phase 3 studies are compared on basis of $\alpha / \beta$ values ranging from $1 \mathrm{~Gy}$ to $10 \mathrm{~Gy}$.

\section{Hypofractionation in adjuvant and salvage treatment}

Data on moderate hypofractionation in postoperative or salvage radiotherapy of prostate cancer are sparse and the few reports available are retrospective in nature. As there are already reports on unexpected high rates of up to $28 \%$ grade 3 late GU toxicity [30, 31] it seems very wise to abstain from hypofractionation in the postoperative setting outside carefully designed clinical trials, keeping in mind that in this situation the target volume irradiated mainly consists of normal tissue.

\section{Current trials in moderate hypofractionation}

As already mentioned, there are several large scale trials that have already completed accrual and published results and hopefully in the near future more details especially subgroup analyses will be presented. The collaborate OCOG/ TROG PROFIT Prostate Fractionated Irradiation Trial (NCT00304759) testing $78 \mathrm{~Gy} / 39$ fractions in 8 weeks vs. $60 \mathrm{~Gy} / 20$ fractions in 4 weeks (i.e. the same regimen as the 20 fractions schedule of the CHHiP trial) for intermediate risk prostate cancer has completed its accrual of more than 1200 men and first results were reported at the American Society of Clinical Oncology Annual Meeting 2016 [32]. Clinicaltrials.gov. lists the Canadian trial on Hypofractionated Dose Escalation Radiotherapy for High Risk Adenocarcinoma of the Prostate 76 Gy/38 fractions vs. $68 \mathrm{~Gy} / 25$ fractions (NCT01444820) and the closed MD Anderson phase III study (NCT00667888), comparing $75.6 \mathrm{~Gy} / 42$ fractions vs. $72 \mathrm{~Gy} / 30$ fractions with no further details. Some insight into the outcomes of extreme vs. moderate hypofractionation may be derived from the HEAT trial, comparing $70.2 \mathrm{~Gy}$ in 26 fractions vs. $36.25 \mathrm{~Gy}$ in 5 fractions (NCT01794403).

\section{Summary on moderate hypofractionation}

There is a growing body of evidence that modern moderately hypofractionated regimens are safe and non-inferior to conventional fractionation in terms of clinical and biochemical recurrence-free survival and late toxicity. Special precaution is needed for particular subgroups of patients with a substantially higher risk of acute GI toxicity and late GU toxicity who apparently are not eligible candidates for hypofractionation. An important caveat in the assessment of hypofractionation in prostate cancer remains the fact that although supportive evidence is growing, the present review and recommendations are limited by the fact of still immature data; therefore, the DEGRO expert panel strongly recommends:

1. To restrict the use of moderate hypofractionation to highend techniques including IGRT and IMRT in carefully selected patients and to adhere to published phase 3 protocols with documented safety and efficacy. The CHHiP regimen with $60 \mathrm{~Gy}$ in 20 fractions over 4 weeks or the RTOG regimen with 70 Gy in 28 fractions over 6 weeks at present seem to be the first choices, although it has to be kept in mind that in the CHHIP trial equivalency was shown only in comparison to 74.0 Gy in standard fractionation, which might be regarded a rather low dose for the patients treated, who predominantly had intermediate risk disease.

2. Meticulous follow-up and documentation of outcome and late toxicity are mandatory.

3. Hypofractionated radiotherapy of the pelvic lymphatic vessels is experimental and should not be carried out except in clinical trials.

4. Hypofractionated radiation therapy in postoperative and in salvage situations is experimental and should not be carried out except in clinical trials.

\section{Extreme hypofractionation}

Extreme hypofractionation with single doses of $>4-10$ Gy up to total doses of $35-50 \mathrm{~Gy}$, is most often applied with stereotactic body radiotherapy (SBRT) techniques. Throughout the last 5 years, a growing number of phase I/II studies as well as retrospective analyses of extreme hypofractionation schedules have been published, with median follow-up periods of roughly 6 years at maximum [33-35]. Four to five fractions of single doses between 7 Gy and 10 Gy have been used, with estimated biologically equivalent doses of up to an EQD2 of 164 Gy [36] applied in only 1-2 weeks; therefore, these regimens are also frequently termed stereotactic ablative radiotherapy (SABR). These very high doses necessitate small PTV margins and utmost precision with respect to both interfraction and intrafraction motion of the prostate. This can be achieved with live tracking image guidance strategies based on fiducials or on electromagnetic beacon transponder technologies. In most of these reports dedicated robotic radiosurgery units were used; alternatively, IGRT-IMRT on specially equipped linacs was performed.

\section{Clinical evidence}

In the vast majority these studies included only low-risk and intermediate-risk patients. For this selections early can- 
cer outcomes have been excellent, with unanimously reported bNED rates of $>90 \%$ up to $100 \%$ in short and midterm follow-up. In the largest single institution study with a 72-month median follow-up, Katz and Kang. [35] treated 515 patients to $35-36.25$ Gy in 5 fractions. Low-risk patients showed a freedom from biochemical failure rate of $95.8 \%$ at 7 years. Results for intermediate and high-risk patients were $89.3 \%$ and $68.5 \%$, respectively. Loblaw et al. [37] treated only low-risk prostate cancer patients and had a similar follow-up of 55 months. The authors noted a 5year biochemical control of $98 \%$, also confirmed in posttreatment biopsies in $85 \%$ of the patients. Out of these, only $4 \%$ were classified positive for residual cancer 3 years after treatment. These excellent results are comparable to a highdose IMRT series obtained in a phase 3 trial for low-risk disease [38].

An overview of trials comprising of at least 50 patients and results following extreme hypofractionation is provided in table 2 [33-35, 37, 39-51]. Additional evidence is provided by the Registry for Prostate Cancer Radiosurgery (RPCR) with an analysis of the largest cohort so far treated by extreme hypofractionated SBRT [43]. Between 2010 and 2013, almost 1750 men from 45 participating sites were enrolled, with the majority $(86 \%)$ receiving SBRT as monotherapy. At 2-year follow-up, biochemical diseasefree survival amounted to $92 \%$, which is in line with the few prospective series. The data presented by Freeman et al. [43] are to some extent limited by incomplete data entry into the database and thus an inherent risk of underreporting of outcomes that were undesired. To what extent these registry data include patients already reported on in other series remains another open question.

\section{Toxicity}

Moderate to high-grade acute toxicity from extreme hypofractionation ranges between $10 \%$ and $20 \%$, with urinary symptoms more common than those related to the bowels and rectum. Late grade 2 toxicity rates from these individual institutional experiences vary significantly (1-31\%), with grade 4 toxicity occasionally reported [36, $37,49]$. While urinary incontinence is uncommon in conventional fractionation, in one study it was reported to be as high as $10 \%$ in previously continent men 3 years postSBRT [52]. Many of the toxicity rates published are crude rates, not taking into account patients lost to follow-up and thus actuarial rates may be in fact higher than reported [4]. Earlier studies have noted particularly high urinary toxicity rates, with late grade 2 rates of up to $30-40 \%$ [50, 53, 54], pointing at the necessity of high quality levels in performing marker-based, image-guided SBRT. The hypothesis of an $\alpha / \beta$ ratio for urethra and bladder that is lower than commonly assumed builds a caveat towards unexpectedly increased late toxicity. In a large retrospective case control study of Medicare claims, 1335 extreme HF-SBRT patients were matched to $2670 \mathrm{CF}$-IMRT patients and 2 years posttreatment, higher late GU toxicity events were noted in the hypofractionated group (43.9\% vs $36.3 \% ; p=0.001$ ) [53]. The increase in GU toxicity was due to claims indicative of urethritis, urinary incontinence and/or obstruction. Treatment on non-consecutive days may reduce late toxicity. One study found lower rates of grade 1-2 urinary $(17 \%$ vs $56 \% ; p=0.007)$ and rectal $(5 \%$ vs $44 \% ; p=0.001)$ toxicity with a regimen of every other day versus daily dosing [33].

A comprehensive overview of the late GI/GU toxicity rates as a function of prescription dose is provided by Koontz et al. comprising the majority of extreme HF study results published at that time [4]. Several of the studies have reported grade 4 GI toxicities (i.e. colostomy) at high total doses. In 1 study patients were treated with 5 fractions of 7 Gy and 2 studies used 9-10 Gy per fraction. An update of a dose-escalation study performed by Boike et al. [36] noted a 2-year actuarial rate of $8 \%$ high-grade GI toxicity in 61 patients receiving $50 \mathrm{~Gy}$ in 5 fractions [55] and 5 patients required a diverting colostomy at a median time of 9.5 months. The volume of rectum receiving $50 \mathrm{~Gy}$ was highly significant on multivariate analysis. Katz et al. [35] noted decreased grade $2 \mathrm{GU}$ toxicity in patients receiving 35 Gy rather than 36.25 Gy in 5 fractions $(5.7 \%$ vs $10.6 \%)$ and overall grade 2 or higher toxicity was significantly higher after $36.25 \mathrm{~Gy}(p=0.05)$. Another study noted increased high-grade rectal toxicity with increasing dose, recommending $<50 \%$ of the rectal volume receiving $4.8 \mathrm{~Gy}$ per fraction [55]. In a series of 204 patients reported by Rana et al., HF-SBRT with 35-36.25 Gy resulted in an acute increase in irritative urinary symptoms that peaked within the first month posttreatment. Irritative voiding symptoms returned to baseline in the majority of patients by 3 months post-SBRT and were actually improved from baseline at 3 years post-SBRT [56]. In the RPCR cohort, no grade 3 late urinary toxicity was reported. One patient developed grade 3 gastrointestinal toxicity (rectal bleeding). Erectile function was preserved in $80 \%$ of men $<70$ years old [43].

\section{Current trials of extreme hypofractionation}

Currently, three phase 3 trials of extreme hypofractionation are active [4]: the Scandinavian Hypofractionated Radiotherapy of Intermediate Risk Localized Prostate Cancer trial (HYPO-RT-PC; ISRCTN45905321) randomizes intermediate-risk men to 42.7 Gy in 7 fractions versus 78 Gy in 39 fractions. The Prostate Advances in Comparative Evidence (PACE) trial, active in multiple European centers, will randomize 1036 men to (1) robotic surgery or prostate SBRT or (2) moderate versus extreme hypofractionation 
Table 2 Major prospective studies on extreme hypofractionated external beam radiotherapy for prostate cancer

\begin{tabular}{|c|c|c|c|c|c|c|c|}
\hline & $n$ & $\begin{array}{l}\text { Median } \\
\text { FU } \\
\text { (months) }\end{array}$ & Risk group & Techniques & $\begin{array}{l}\text { Regimen } \\
(\mathrm{TD} / \mathrm{fx})\end{array}$ & Outcome & Toxicity \\
\hline Aluwini [39] & 162 & 28 & $\begin{array}{l}\text { Low/ } \\
\text { intermediate }\end{array}$ & n. s. & $38 \mathrm{~Gy} / 4 \mathrm{fx}$ & BC $98 \% @ 3$ years & $\begin{array}{l}\text { G } 2 \text { GU } 15 \% \\
\text { G } 2 \text { GI } 3 \%\end{array}$ \\
\hline Bolzicco [40] & 100 & 36 & $\begin{array}{l}41 \% \text { low } \\
42 \% \text { intermedi- } \\
\text { ate } \\
17 \% \text { high }\end{array}$ & $\begin{array}{l}\text { Robotic } \\
\text { IGRT }\end{array}$ & $\begin{array}{l}35 \mathrm{~Gy} / 5 \mathrm{fx} \\
29 \% \mathrm{ADT}\end{array}$ & BC $96 \%$ & $\begin{array}{l}\mathrm{G} 1 / 2 / 3 \mathrm{GU} \\
4 \% / 3 \% / 1 \% \\
\mathrm{G} 1 / 2 / 3 \mathrm{GI} \\
2 \% / 1 \%\end{array}$ \\
\hline Chen et al. [41] & 100 & 28 & $\begin{array}{l}37 \% \text { low } \\
55 \% \text { intermedi- } \\
\text { ate } \\
8 \% \text { high }\end{array}$ & $\begin{array}{l}\text { Robotic } \\
\text { IGRT }\end{array}$ & $\begin{array}{l}35-36.25 \\
\text { Gy/5 fx } \\
11 \% \text { ADT }\end{array}$ & BRFS99\%@2 years & $\begin{array}{l}2 \text { y } G \geq 2 \mathrm{GU} \\
31 \% \\
2 \text { y G } \geq 2 \text { GI } 1 \%\end{array}$ \\
\hline $\begin{array}{l}\text { D'Alimonte et al. } \\
\text { [42] }\end{array}$ & 84 & 50 & $100 \%$ low & $\begin{array}{l}\text { IMRT/ } \\
\text { IGRT }\end{array}$ & $35 \mathrm{~Gy} / 5 \mathrm{fx}$ & BC $98 \%$ & $\begin{array}{l}\text { G } 2 / \geq 3 \text { GU } 5 / 1 \% \\
\text { G } 2 / \geq 3 \text { GI } 5 / 1 \%\end{array}$ \\
\hline $\begin{array}{l}\text { Friedland } \\
\text { et al.[34] }\end{array}$ & 122 & 24 & $\begin{array}{l}72 \% \text { low } \\
28 \% \text { intermedi- } \\
\text { ate }+ \\
\text { high }\end{array}$ & $\begin{array}{l}\text { Robotic } \\
\text { IGRT }\end{array}$ & $\begin{array}{l}35 \mathrm{~Gy} / 5 \mathrm{fx}- \\
36.3 \mathrm{~Gy} / 5 \mathrm{fx} \\
19 \% \mathrm{ADT}\end{array}$ & FFBF $97 \%$ & $\begin{array}{l}\text { G } 3+\text { GU } 0 \% \\
\text { G } 3+\text { GI } 1 \%\end{array}$ \\
\hline $\begin{array}{l}\text { Freeman (2015) } \\
\text { (RPCR registry) }\end{array}$ & 1743 & $n . \mathrm{s}$. & $\begin{array}{l}41 \% \text { low } \\
42 \% \text { intermedi- } \\
\text { ate } \\
10 \% \text { high } \\
7 \% \text { data missing }\end{array}$ & $\begin{array}{l}\text { Mainly } \\
\text { robotic } \\
\text { IGRT }\end{array}$ & $\begin{array}{l}35-40 \mathrm{~Gy} / \\
4-5 \mathrm{fx} \\
(8 \% \\
\text { SBRT-boost } \\
19.5-21.8 \mathrm{~Gy} / \\
3 \mathrm{fx} \text { after } \\
45-50 \mathrm{~Gy} \\
\text { EBRT) }\end{array}$ & $\begin{array}{l}\text { FFBF } 92 \% @ 2 \text { years } \\
99 \% \text { low risk } \\
97-85 \% \text { interm. } \\
87 \% \text { high }\end{array}$ & $\begin{array}{l}\text { G3 GU } 0 \% \\
\text { G3 GI } 0 \%\end{array}$ \\
\hline Fuller et al. [44] & 260 & 20 & $\begin{array}{l}45 \% \text { low } \\
55 \% \text { intermedi- } \\
\text { ate }\end{array}$ & n.s. & $38 \mathrm{~Gy} / 4 \mathrm{fx}$ & BRFS98\%@3 years & $\begin{array}{l}\text { G } 3 \text { GU } 2 \% \\
\text { (any G } 44 \% \text { ) } \\
\text { G } 3 \text { GI } 0 \% \\
\text { (any G } 11 \% \text { ) }\end{array}$ \\
\hline $\begin{array}{l}\text { Katz and Kang } \\
\text { [35] }\end{array}$ & 515 & 72 & $\begin{array}{l}63 \% \text { low } \\
30 \% \text { intermedi- } \\
\text { ate } \\
7 \% \text { high }\end{array}$ & $\begin{array}{l}\text { Robotic } \\
\text { IGRT }\end{array}$ & $\begin{array}{l}35-36.25 \\
\text { Gy/5 fx }\end{array}$ & $\begin{array}{l}\text { FFBF @ } 7 \text { years } \\
96 \% \text { (low risk) } \\
89 \% \text { (interm.r.) } \\
69 \% \text { (high risk) }\end{array}$ & $\begin{array}{l}\mathrm{G} \geq 2 \text { GU } 9 \% \\
\mathrm{G} \geq 2 \text { GI } 4 \%\end{array}$ \\
\hline King et al. [33] & 67 & 32 & $100 \%$ low & $\begin{array}{l}\text { Robotic } \\
\text { IGRT }\end{array}$ & $36.25 \mathrm{~Gy} / 5 \mathrm{fx}$ & $92 \%$ & $\begin{array}{l}G \geq 2 \text { GU } 7 \% \\
G \geq 2 \text { GI } 12 \%\end{array}$ \\
\hline Loblaw et al. [37] & 84 & 55 & $100 \%$ low & $\begin{array}{l}\text { IMRT/ } \\
\text { IGRT }\end{array}$ & $35 \mathrm{~Gy} / 5 \mathrm{fx}$ & $70 \%$ & $\begin{array}{l}5 \text { y G } \geq 2 \text { GU } 5 \% \\
5 \text { y G } \geq 2 \text { GI } 7 \%\end{array}$ \\
\hline Lukka et al. [45] & 240 & n. s. & Low & $\begin{array}{l}\text { IMRT/ } \\
\text { IGRT }\end{array}$ & $\begin{array}{l}36.3 \mathrm{~Gy} / 5 \mathrm{fx} \\
51.6 \mathrm{~Gy} / 12 \mathrm{fx}\end{array}$ & n.s. & $\begin{array}{l}\text { Changes in EPIC } \\
\text { bowel \& urinary } \\
\text { domain scores: } \\
\text { both regimens } \\
\text { well tolerated }\end{array}$ \\
\hline Mantz et al. [46] & 91 & 24 & $\begin{array}{l}\text { Low and inter- } \\
\text { mediate }\end{array}$ & $\begin{array}{l}\text { IMRT/ } \\
\text { IGRT }\end{array}$ & $\begin{array}{l}36.3 \mathrm{~Gy} / 5 \mathrm{fx} \\
22.0 \mathrm{~Gy} / 4 \mathrm{fx}\end{array}$ & FFBF $97 \%$ & $\begin{array}{l}\text { G } 3+\text { GU } 5 \% \\
\text { G } 3+\text { GI } 1 \%(\mathrm{G} 4)\end{array}$ \\
\hline $\begin{array}{l}\text { Meier et al. [47, } \\
48]\end{array}$ & 129 & 30 & $\begin{array}{l}100 \% \text { intermedi- } \\
\text { ate }\end{array}$ & $\begin{array}{l}\text { Robotic } \\
\text { IGRT }\end{array}$ & $\begin{array}{l}40 \mathrm{~Gy} / 5 \mathrm{fx} \\
\text { No ADT }\end{array}$ & BRFS94\%@4years & $\begin{array}{l}\text { G } 2 \text { GU } 10 \% \\
\text { G } 2 \text { GI } 2 \%\end{array}$ \\
\hline $\begin{array}{l}\text { Menkarios et al. } \\
\text { [49] }\end{array}$ & 80 & 33 & $100 \%$ low & $\begin{array}{l}\text { IMRT/ } \\
\text { IGRT }\end{array}$ & $45 \mathrm{~Gy} / 5 \mathrm{fx}$ & BC $98 \% @ 5$ years & $\begin{array}{l}\mathrm{G} \geq 2 \text { GU } 14 \% \\
\mathrm{G} \geq 2 \text { GI } 16 \%\end{array}$ \\
\hline Oliai et al. [50] & 70 & 37 & $\begin{array}{l}51 \% \text { low } \\
31 \% \text { intermedi- } \\
\text { ate } \\
17 \% \text { high }\end{array}$ & $\begin{array}{l}\text { Robotic } \\
\text { IGRT }\end{array}$ & $\begin{array}{l}35 \mathrm{~Gy} / 5 \mathrm{fx} \\
36.3 \mathrm{~Gy} / 5 \mathrm{fx} \\
37.5 \mathrm{~Gy} / 5 \mathrm{fx} \\
33 \% \text { ADT }\end{array}$ & $\begin{array}{l}\text { FFBF } \\
100 \% / 95 \% / 77 \%\end{array}$ & $\begin{array}{l}\text { G } 3+\text { GU } 3 \% \\
\text { G } 3+\text { GI } 0 \%\end{array}$ \\
\hline Quon et al. [51] & 84 & 18 & $100 \%$ low & $\begin{array}{l}\text { IMRT/ } \\
\text { IGRT }\end{array}$ & $35 \mathrm{~Gy} / 5 \mathrm{fx}$ & BRFS 99\%@3y & $\begin{array}{l}\text { G } 2 \text { GU } 2 \% \\
\text { G } 2 \text { GI } 5 \%\end{array}$ \\
\hline
\end{tabular}

$A D T$ androgen deprivation therapy, $B C$ biochemical control, $B R F S$ biochemical relapse-free survival, $F F B F$ freedom from biochemical failure, $F U$ follow-up, $T$ total dose, $f x$ number of fractions, $G I$ gastrointestinal, $G$ grade, $G U$ genitourinary, IGRT image-guided radiation therapy, IMRT intensity-modulated radiation therapy, $n$. s. not stated, EBRT external beam radiotherapy in standard fractionation. 
with 5-year biochemical progression-free survival as the primary end point (NCT01584258). A similar approach is tested by the RTOG in a phase II randomized multicenter trial to assess quality of life outcomes, acute and late toxicity of two different extreme hypofractionated regimens: 36.25 Gy in 5 fractions of 7.25 Gy twice a week and 51.6 Gy in 12 daily fractions of 4.3 Gy (RTOG 0938, NCT01434290). Finally, the Proton Cooperative Group is randomizing 192 patients in a phase 3 study of 79.2 Gy in 44 fractions or 38 Gy in 5 fractions, using a primary end point of 5-year freedom from failure (NCT01230866). All these studies are still recruiting, and results are pending.

\section{Summary}

In selected non-randomized cohorts, clinical outcome following extreme hypofractionation regimens for low-risk prostate cancer shows good short and mid-term biochemical control up to 5 years, well comparable with current conventional high-dose fractionation. The American Society for Radiation Oncology recently released their policy on SBRT stating that while longer outcome is still necessary, it is regarded suitable to offer SBRT to selected low and intermediate-risk prostate cancer patients; however, in the light of the reports of higher grade urinary and rectal toxicity and in the absence of long-term experience derived from randomized controlled trials, the DEGRO expert panel strongly discourages its use outside prospective clinical protocols.

\section{Hypofractionated radiotherapy with protons and ions}

\section{Prerequisites}

Particle therapy of prostate cancer is currently not routine procedure. As there are potential benefits due to the physical differences in dose distribution compared to photon therapy, there is an increasing interest. Physically, it is possible to focus the particles in the tumor while minimizing the dose to the surrounding healthy tissue; therefore, the beneficial dose distribution might reduce the risks of longterm toxicity (assuming similar fractionation and dose concepts). Also, a reduction of radiation-associated secondary cancers is postulated due to the reduced dose in surrounding tissues; however, in clinical routine the same requirements are necessary as for photon therapy: in particular, a daily verification of target volumes immediately before irradiation (image guided proton therapy, IGPT) is essential. As the range of protons is very sensitive to the density of irradiated tissue, the set-up alignment focuses on bony structures in the beam; therefore, in contrast to photon therapy, the interfractional movement of the prostate cannot be easily corrected. This can only be compensated partly by careful preparation of the patient (e.g. rectal balloon, fiducials).

From the radiobiological point of view, there might be (after application of correction factors) probably little difference between radiotherapy for prostate cancer with protons or photons. In the hypofractionated setting this might be an issue, especially in Germany with respect to approval and regulations [57].

\section{Clinical data}

The information on carbon ion therapy for prostate cancer is very limited. Many of the reports originate from centers with much experience in particle therapy, mainly from Japan but are retrospective in nature and only very few cover a number of patients that will allow valid conclusions to be drawn $[58,59]$. Prospective studies are usually of even smaller size [60]. Data on proton therapy are more robust, and proton therapy in standard fractionation is in routine use in many centers for definitive treatment of prostate cancer and detailed information is available $[38,61]$. In a small phase 3 study, Vargas et al. [62] compared standard fractionated proton therapy with $79.2 \mathrm{GyE}$ in 44 treatments with an extremely hypofractionated schedule of $38 \mathrm{GyE}$ in 5 fractions. There were no major differences at an interim analysis although the American Urological Association Symptom Index at 12 months did show a significant deterioration $(p=0.04)$ in the hypofractionated arm. A median follow-up of only 18 months and a total number of patients of 82 limit the possibility of further interpretation. Finally, the Heidelberg University ion facility recently finished a pilot study to compare hypofractionated therapy with carbon ions to protons [63].

In summary, the DEGRO expert panel recommends that hypofractionation with heavy ions should not be used outside clinical trials.

In absence of long-term experience derived from randomized controlled trials, the DEGRO expert panel recommends the use of hypofractionated proton therapy in prostate cancer in prospective clinical protocols.

Acknowledgements The authors are very grateful to Dr. Detlef Bartkowiak, Department of Radiation Oncology, University Hospital Ulm, Germany for his help and contribution in preparing and correcting the manuscript.

Conflict of interests S. Höcht, D.M. Aebersold, C. Albrecht, D. Böhmer, M. Flentje, U. Ganswindt, T. Hölscher, T. Martin, F. Sedlmayer, F. Wenz, D. Zips and T. Wiegel state that they have no conflict of interests.

The accompanying manuscript does not contain any studies carried out by the authors on humans or animals. 
Open Access This article is distributed under the terms of the Creative Commons Attribution 4.0 International License (http:// creativecommons.org/licenses/by/4.0/), which permits unrestricted use, distribution, and reproduction in any medium, provided you give appropriate credit to the original author(s) and the source, provide a link to the Creative Commons license, and indicate if changes were made.

\section{References}

1. Budach W, Matuschek C, Bolke E et al (2015) DEGRO practical guidelines for radiotherapy of breast cancer V: therapy for locally advanced and inflammatory breast cancer, as well as local therapy in cases with synchronous distant metastases. Strahlenther Onkol 191:623-633

2. Whelan TJ, Pignol JP, Levine MN et al (2010) Long-term results of hypofractionated radiation therapy for breast cancer. N Engl J Med 362:513-520

3. Haviland JS, Owen JR, Dewar JA et al (2013) The UK Standardisation of Breast Radiotherapy (START) trials of radiotherapy hypofractionation for treatment of early breast cancer: 10-year follow-up results of two randomised controlled trials. Lancet Oncol 14:1086-1094

4. Koontz BF, Bossi A, Cozzarini C et al (2015) A systematic review of hypofractionation for primary management of prostate cancer. Eur Urol 68:683-691

5. Baumann M, Hölscher T, Denham J (2010) Fractionation in prostate cancer - is it time after all? Radiother Oncol 96:1-5

6. Thames HD, Kuban D, Levy LB et al (2010) The role of overall treatment time in the outcome of radiotherapy of prostate cancer: an analysis of biochemical failure in 4839 men treated between 1987 and 1995. Radiother Oncol 96:6-12

7. Vogelius IR, Bentzen SM (2013) Meta-analysis of the alpha/beta ratio for prostate cancer in the presence of an overall time factor: bad news, good news, or no news? Int J Radiat Oncol Biol Phys 85:89-94

8. Pollack A, Hanlon AL, Horwitz EM et al (2006) Dosimetry and preliminary acute toxicity in the first 100 men treated for prostate cancer on a randomized hypofractionation dose escalation trial. Int J Radiat Oncol Biol Phys 64:518-526

9. Boehmer D, Maingon P, Poortmans P et al (2006) Guidelines for primary radiotherapy of patients with prostate cancer. Radiother Oncol 79:259-269

10. Deutschmann H, Kametriser G, Steininger P et al (2012) First clinical release of an online, adaptive, aperture-based image-guided radiotherapy strategy in intensity-modulated radiotherapy to correct for inter- and intrafractional rotations of the prostate. Int J Radiat Oncol Biol Phys 83:1624-1632

11. Lee WR, Dignam JJ, Amin MB et al (2016) Randomized phase III noninferiority study comparing two radiotherapy fractionation schedules in patients with low-risk prostate cancer. J Clin Oncol 34:2325-2332

12. Lukka H, Hayter C, Julian JA et al (2005) Randomized trial comparing two fractionation schedules for patients with localized prostate cancer. J Clin Oncol 23:6132-6138

13. Aluwini S, Pos F, Schimmel E et al (2016) Hypofractionated versus conventionally fractionated radiotherapy for patients with prostate cancer (HYPRO): late toxicity results from a randomised, non-inferiority, phase 3 trial. Lancet Oncol 17:464-474

14. Aluwini S, Pos F, Schimmel E et al (2015) Hypofractionated versus conventionally fractionated radiotherapy for patients with prostate cancer (HYPRO): acute toxicity results from a randomised non-inferiority phase 3 trial. Lancet Oncol 16:274-283

15. Incrocci L, Wortel RC, Alemayehu WG et al (2016) Hypofractionated radiotherapy for patients with localised prostate cancer
(HYPRO): Final efficacy results from a randomised, multicentre, open-label, phase3 trial. Lancet Oncol 17(8):1061-1069. doi:10. 1016/s1470-2045(16)30070-5

16. Dearnaley D, Syndikus I, Mossop H et al (2016) Conventional versus hypofractionated high-dose intensity-modulated radiotherapy for prostate cancer: 5-year outcomes of the randomised, non-inferiority, phase3 CHHIP trial. Lancet Oncol 17:1047-1060

17. Dearnaley D, Syndikus I, Sumo G et al (2012) Conventional versus hypofractionated high-dose intensity-modulated radiotherapy for prostate cancer: preliminary safety results from the CHHiP randomised controlled trial. Lancet Oncol 13:43-54

18. Pollack A, Walker G, Horwitz EM et al (2013) Randomized trial of hypofractionated external-beam radiotherapy for prostate cancer. J Clin Oncol 31:3860-3868

19. Shaikh T, Li T, Johnson ME et al (2015) Long-term patient reported outcomes from a phase 3 randomized prospective trial of conventional versus hypofractionated IMRT radiation therapy for localized prostate cancer. Int J Radiat Oncol Biol Phys 93:S34-S36

20. Yeoh EE, Botten RJ, Butters J et al (2011) Hypofractionated versus conventionally fractionated radiotherapy for prostate carcinoma: final results of phase III randomized trial. Int J Radiat Oncol Biol Phys 81:1271-1278

21. Kuban D, Nogueras-Gonzalez GM, Hamblin L et al (2010) Preliminary report of a randomized dose escalation trial for prostate cancer using hypofractionation. Int J Radiat Oncol Biol Phys 78:S58-59

22. Hoffman KE, Voong KR, Pugh TJ et al (2014) Risk of late toxicity in men receiving dose-escalated hypofractionated intensity modulated prostate radiation therapy: results from a randomized trial. Int J Radiat Oncol Biol Phys 88:1074-1084

23. Arcangeli G, Fowler J, Gomellini S et al (2011) Acute and late toxicity in a randomized trial of conventional versus hypofractionated three-dimensional conformal radiotherapy for prostate cancer. Int J Radiat Oncol Biol Phys 79:1013-1021

24. Arcangeli G, Saracino B, Gomellini S et al (2010) A prospective phase III randomized trial of hypofractionation versus conventional fractionation in patients with high-risk prostate cancer. Int J Radiat Oncol Biol Phys 78:11-18

25. Arcangeli S, Strigari L, Gomellini S et al (2012) Updated results and patterns of failure in a randomized hypofractionation trial for high-risk prostate cancer. Int J Radiat Oncol Biol Phys 84:1172-1178

26. Yeoh EE, Holloway RH, Fraser RJ et al (2006) Hypofractionated versus conventionally fractionated radiation therapy for prostate carcinoma: updated results of a phase III randomized trial. Int J Radiat Oncol Biol Phys 66:1072-1083

27. Tramacere F, Arcangeli S, Pignatelli A et al (2015) Hypofractionated dose escalated 3D conformal radiotherapy for prostate cancer: outcomes from a mono-institutional phase II study. Anticancer Res 35:3049-3054

28. McDonald AM, Baker CB, Shekar K et al (2014) Reduced radiation tolerance of penile structures associated with dose-escalated hypofractionated prostate radiotherapy. Urology 84:1383-1387

29. Putora PM, Engeler D, Haile SR et al (2016) Erectile function following brachytherapy, external beam radiotherapy, or radical prostatectomy in prostate cancer patients. Strahlenther Onkol 192:182-189

30. Cozzarini C, Fiorino C, Deantoni C et al (2014) Higher-than-expected severe (Grade 3-4) late urinary toxicity after postprostatectomy hypofractionated radiotherapy: a single-institution analysis of 1176 patients. Eur Urol 66:1024-1030

31. Lewis SL, Patel P, Song H et al (2016) Image guided hypofractionated postprostatectomy intensity modulated radiation therapy for prostate cancer. Int J Radiat Oncol Biol Phys 94:605-611

32. Catton CN, Lukka H, Julian JA et al (2016) A randomized trial of a shorter radiation fractionation schedule for the treatment of localized prostate cancer. J Clin Oncol 34:A5003 
33. King CR, Brooks JD, Gill Presti HJC Jr. (2012) Long-term outcomes from a prospective trial of stereotactic body radiotherapy for low-risk prostate cancer. Int J Radiat Oncol Biol Phys 82:877-882

34. Friedland JL, Freeman DE, Masterson-McGary ME et al (2009) Stereotactic body radiotherapy: an emerging treatment approach for localized prostate cancer. Technol Cancer Res Treat 8:387-392

35. Katz AJ, Kang J (2014) Quality of life and toxicity after SBRT for organ-confined prostate cancer, a 7-year study. Front Oncol 4:301

36. Boike TP, Lotan Y, Cho LC et al (2011) Phase I dose-escalation study of stereotactic body radiation therapy for low- and intermediate-risk prostate cancer. J Clin Oncol 29:2020-2026

37. Loblaw A, Cheung P, D'Alimonte L et al (2013) Prostate stereotactic ablative body radiotherapy using a standard linear accelerator: toxicity, biochemical, and pathological outcomes. Radiother Oncol 107:153-158

38. Zietman AL, Bae K, Slater JD et al (2010) Randomized trial comparing conventional-dose with high-dose conformal radiation therapy in early-stage adenocarcinoma of the prostate: long-term results from proton radiation oncology group/american college of radiology 95-09. J Clin Oncol 28:1106-1111

39. Aluwini S, Beltramo G, Van Rooij P et al (2013) Stereotactic body radiotherapy with four fractions for low- and intermediate-risk prostate cancer: acute and late toxicity. Eur Urol 12:156

40. Bolzicco G, Favretto MS, Satariano N et al (2013) A single-center study of 100 consecutive patients with localized prostate cancer treated with stereotactic body radiotherapy. BMC Urol 13:49

41. Chen LN, Suy S, Uhm S et al (2013) Stereotactic body radiation therapy (SBRT) for clinically localized prostate cancer: the Georgetown University experience. Radiat Oncol 8:58

42. D'Alimonte L, Loblaw A, Cheung P et al (2013) Long term outcomes of a novel five fraction hypofractionated protocol for low risk prostate cancer. J Med Imaging Radiat Sci 44:44-58

43. Freeman D, Dickerson G, Perman M (2015) Multi-institutional registry for prostate cancer radiosurgery: a prospective observational clinical trial. Front Oncol 4:369

44. Fuller DB, Mardirossian G, Wong D et al (2012) Prospective evaluation of stereotactic body radiation therapy for low- and intermediate-risk prostate cancer: emulating high-dose-rate brachytherapy dose distribution. Int J Radiat Oncol Biol Phys 84:S149

45. Lukka H, Stephanie P, Bruner D et al (2016) Patient-reported outcomes in NRG oncology/RTOG 0938, a randomized phase 2 study evaluating 2 ultrahypofractionated regimens (UHRs) for prostate cancer. Int J Radiat Oncol Biol Phys 94(1):2

46. Mantz CA, Fernandez E, Zucker Harrison IS (2009) A phase II trial of Varian trilogy-based SBRT for low-risk prostate cancer: report of early toxicity and disease control outcomes. Int J Radiat Oncol Biol Phys 75:S326

47. Meier R, Kaplan I, Beckman A et al (2012) Stereotactic body radiation therapy for intermediate-risk organ-confined prostate cancer: interim toxicity and quality of life outcomes from a multi-institutional study. Int J Radiat Oncol Biol Phys 84:S148

48. Meier R, Kaplan I, Beckman A et al (2013) Patient-reported quality of life outcomes in intermediate-risk prostate cancer patients treated with stereotactic body radiation therapy. Int J Radiat Oncol Biol Phys 87:S25

49. Menkarios C, Vigneault E, Brochet N et al (2011) Toxicity report of once weekly radiation therapy for low-risk prostate adenocarcinoma: preliminary results of a phase I/II trial. Radiat Oncol 6:112

50. Oliai C, Lanciano R, Sprandio B et al (2013) Stereotactic body radiation therapy for the primary treatment of localized prostate cancer. J Radiat Oncol 2:63-70

51. Quon H, Cheung P, Cesta A et al (2010) Prospective study of extreme hypofractionated radiotherapy ( $35 \mathrm{GY}$ in five fractions) for low-risk prostate cancer: toxicity results. Radiother Oncol 96:S46

52. Chen LN, Suy S, Wang H et al (2014) Patient-reported urinary incontinence following stereotactic body radiation therapy (SBRT) for clinically localized prostate cancer. Radiat Oncol 9:148

53. Yu JB, Cramer LD, Herrin J et al (2014) Stereotactic body radiation therapy versus intensity-modulated radiation therapy for prostate cancer: comparison of toxicity. J Clin Oncol 32:1195-1201

54. Behrendt K, Nowicka E, Gawkowska-Suwinska M et al (2014) Early closure of phase II prospective study on acute and late tolerance of hypofractionated radiotherapy in low-risk prostate cancer patients. Rep Pract Oncol Radiother 19:337-342

55. Kim DW, Cho LC, Straka C et al (2014) Predictors of rectal tolerance observed in a dose-escalated phase 1-2 trial of stereotactic body radiation therapy for prostate cancer. Int J Radiat Oncol Biol Phys 89:509-517

56. Rana Z, Cyr RA, Chen LN et al (2014) Improved irritative voiding symptoms 3 years after stereotactic body radiation therapy for prostate cancer. Front Oncol 4:290

57. Simon M, Habeck M, Büttner D et al (2015) Approval procedures for clinical trials in the field of radiation oncology. Strahlenther Onkol 191:909-920

58. Ishikawa H, Tsuji H, Kamada T et al (2006) Carbon ion radiation therapy for prostate cancer: results of a prospective phase II study. Radiother Oncol 81:57-64

59. Okada T, Tsuji H, Kamada T et al (2012) Carbon ion radiotherapy in advanced hypofractionated regimens for prostate cancer: from 20 to 16 fractions. Int J Radiat Oncol Biol Phys 84:968-972

60. Nomiya T, Tsuji H, Maruyama K et al (2014) Phase I/II trial of definitive carbon ion radiotherapy for prostate cancer: evaluation of shortening of treatment period to 3 weeks. Br J Cancer 110:2389-2395

61. Mendenhall NP, Hoppe BS, Nichols RC et al (2014) Five-year outcomes from 3 prospective trials of image-guided proton therapy for prostate cancer. Int J Radiat Oncol Biol Phys 88:596-602

62. Vargas CE, Hartsell WF, Dunn M et al (2015) Hypofractionated versus standard fractionated proton-beam therapy for low-risk prostate cancer: interim results of a randomized trial PCG GU 002. Am J Clin Oncol. doi:10.1097/COC.0000000000000241

63. Habl G, Hatiboglu G, Edler L et al (2014) Ion Prostate Irradiation (IPI) - a pilot study to establish the safety and feasibility of primary hypofractionated irradiation of the prostate with protons and carbon ions in a raster scan technique. BMC Cancer 14:202 